\title{
What Bergson should have said about special relativity
}

\author{
Peter Kügler ${ }^{1}$ \\ Received: 11 December 2019 / Accepted: 20 May 2020 / Published online: 28 May 2020 \\ (c) The Author(s) 2020
}

\begin{abstract}
The debate between Einstein and Bergson is a salient episode in the history of modern physics and a telling example of the interaction between science and philosophy. This paper initially discusses five reasons why Bergson criticised Einstein for giving up absolute time. The most important one was Bergson's commitment to an intuitionist, anti-Kantian metaphysics informed by common sense. Apart from that, he knew that the theory of special relativity permits "duration" (durée) in the form of the passage of proper time, to which Bergson referred as "real time". Neither static eternalism (which excludes temporal passage) nor dynamic eternalism (which, like the former, claims the existence of the future) are acceptable from Bergson's philosophical perspective, which acknowledges the role of temporal experience and everyday thinking in addition to science and metaphysics. He understood temporal passage as creation of new existence, anticipating what later became known as the growing block theory of time. The pointy relativistic variant of this theory, which divides the universe into blocks of growing past light cones, does justice to large parts of his philosophy, including the distinction between the actual and the virtual. Supporters of Bergson's account of duration should adopt this theory of time.
\end{abstract}

Keywords Bergson - Special relativity - Duration - Temporal passage - Proper time · Growing block theory

\section{Introduction}

After the famous debate between Henri Bergson and Albert Einstein in Paris in 1922, the world gradually became convinced that Bergson had lost the game. However, at the time of the debate, the case was undecided. Compared to Einstein, Bergson enjoyed far greater standing within public opinion. Einstein had only recently become known beyond scientific circles, and when he received the Nobel Prize in Physics later in

\footnotetext{
Peter Kügler

peter.kuegler@uibk.ac.at

1 Department of Philosophy, University of Innsbruck, Innrain 52d, 6020 Innsbruck, Austria
} 
the same year (retrospectively for 1921), Svante Arrhenius, who chaired the prize committee, did not fail to mention "that the famous philosopher Bergson in Paris has challenged this theory, while other philosophers have acclaimed it wholeheartedly" (Arrhenius 1967, p. 479). He was referring, of course, to the theory of relativity. Since these events, much has been written about how and why Bergson's critique missed its target. Some defenders of Einstein argued that the French philosopher did not understand the physics behind special relativity (Topper 2013, p. 131). However, a close reading of Duration and Simultaneity, also published in 1922, shows that Bergson knew enough about special relativity to understand its consequences for the concept of time. Nevertheless, he viewed the theory as false and "surprisingly turned into a defender of Newtonian time" (Čapek 1971, p. 250).

The next section will examine why Bergson defended a conception of time that Einstein had abandoned. I will review five answers to this question, of which the fourth and fifth were decisive: the appeal to intellectual intuition and to common sense. According to the second answer on the list, Bergson rejected the special theory of relativity because he thought that it excluded temporal passage. However, I will describe, in Sect. 3.1, how temporal passage, as conceived by Bergson, can be integrated into special relativity if understood as passage of local or proper time.

While this has been suggested before (Čapek 1971, pp. 238-256), Bergson's additional assumption that the past exists and grows in time has largely been neglected, at least in discussions of his criticism of special relativity. This assumption is today known as the "growing universe" or "growing block" theory of time and had already appeared in books that Bergson published around the turn of the twentieth century. While he conceived of the theory in terms of absolute time, it can be made consistent with special relativity, yielding a relativistic growing block theory (Correia and Rosenkranz 2018, pp. 149-150)—with specific Bergsonian ingredients, such as the distinction between actual and virtual existence.

The growing block theory and its relativistic variation will be addressed in Sects. 3.2 and 3.3 below. In addition, I will confront Bergson's philosophy of time with two kinds of eternalism in Sects. 3.1 and 3.2. Although Bergson briefly considers the relation between special relativity and general relativity in the final pages of Duration and Simultaneity, the theory of general relativity had a very limited role in the debate between Einstein and Bergson, and their respective followers. Accordingly, I will base my exposition solely on the theory of special relativity, which I henceforth abbreviate as STR. ${ }^{1}$

This essay is aimed at three types of reader. First, those interested in the history of modern physics are perhaps curious to know the reasons for Bergson's rejection of STR, given that the encounter between Einstein and Bergson is a salient episode in this history and a telling example of the interaction between science and philosophy.

Second, readers who are primarily interested in Bergson's philosophy and find his account of time and temporal experience prima facie convincing might still be concerned about its compatibility with STR. In addition, they might look for elucidation

\footnotetext{
1 Nevertheless, the relativistic growing block theory to be discussed in Sect. 3.3 seems to work in general relativity as well, if space-time does not contain closed time-like curves.
} 
of some of his conceptual devices, including "real time" as well as "actual" versus "virtual", whose meanings are often blurred by Bergson's literary style of writing.

Finally, those familiar with current discussions in the metaphysics of time will know that although STR is traditionally taken as an argument for eternalism ("past, present, and future exist"), there are also relativistic versions of presentism ("only the present exists") and the growing block theory ("past and present exist"). Philosophical arguments that are independent of STR — or of physics in general—might help in deciding between these theoretical alternatives. Bergson's philosophy is one available path after the obstacles have been removed.

\section{The reasons for Bergson's error}

\subsection{The objectification of psychological time}

Why did Bergson defend a conception of time that Einstein had successfully left behind? Commentators have identified a number of reasons for this error. The first was brought forward by Einstein himself, who regarded Duration and Simultaneity as an attempt to objectify psychological time (Canales 2015, p. 46). ${ }^{2}$ This psychological time is Bergson's "duration" (durée in French), which he had introduced in his first book, published in 1889 and translated into English as Time and Free Will.

Regarding the development of Bergson's view of duration, Einstein was certainly correct as to its psychological origin. In Time and Free Will, Bergson argued that duration exists exclusively in the mind and "that there is neither duration nor even succession in space, if we give to these words the meaning in which consciousness takes them" (1910, p. 120). In later publications, however, he abandoned this purely psychological view of duration and admitted that duration exists in the physical world as well (Čapek 1971, p. 204). Above all, his eventual criticism of STR presupposes this account. Otherwise, he could not have blamed physics for misconstruing duration. The transfer of the notion of duration from the context of psychology to that of physics can arguably be regarded as an "objectification" of psychological time. This step alone was unproblematic, but it seduced Bergson to attribute properties to physical time that contradict STR.

That the objectification of psychological time cannot be blamed for Bergson's "prejudices about time" (Ray 1991, p. 25) becomes clear when we consider that physicists bridge the gap between psychology and physics as well, for example, when they speak of observers who experience time. These observers are typically assumed to read clocks resting in their respective frame of reference. Bergson also mentions such observers in Duration and Simultaneity, writing in one place that "the physicist's consciousness has lived a certain duration; the motion of the clock hands is a flow contemporaneous with this inner flow and serves to measure it" (1965, p. 70).

In physics, though, reference to observers is just a pedagogical device, since STR also holds in a world without sentient beings. Nevertheless, this indicates that it is

\footnotetext{
${ }^{2}$ See the differing translations from Einstein's travel diary for 9 October 1922 in Canales (2015, p. 373). In German, Einstein writes of Bergson's "Objektivierung des Psychisch-Gegebenen” (Einstein 2012, p. 533).
} 
natural to think that the time experienced by a person can coincide with the time shown by a clock. Psychological time could be as relative as physical time, as far as temporal experience is concerned. Therefore, the psychological origin of the concept of duration by itself does not explain Bergson's error.

\section{2 (No) duration in STR}

The second reason found in the literature is that Bergson suspected that STR excluded duration, which in turn implies that he confused STR with its static interpretation-that is, with the view that time does not pass in the physical realm. Milič Čapek argues along these lines that the static interpretation of space-time "apparently concealed from Bergson its true dynamic significance. It was this opposition which drove him back to an unconscious acceptance of the Newtonian idea of space separable from time" (1971, p. 252).

Čapek underpins this argument by mentioning that Bergson "was never tired of criticizing various forms of the spatialization of time". This refers to one of Bergson's central ideas: that we cannot capture the essence of time by assimilating it to space. One form of spatialization of time is measurement: "Pure duration, that which consciousness perceives, [...] is not a quantity, and as soon as we try to measure it, we unwittingly replace it by space" (Bergson 1910, p. 106). Another form is representing it by space-for example, we may represent a duration of sixty-seconds by sixty points on a line (Bergson 1910, p. 104), but the same line can also serve as a representation of a spatial distance and therefore does not show what distinguishes time from space.

However, it would be wrong to understand this criticism in too strong a sense. At no point does Bergson deny the possibility of measuring time and representing it by spatial distances. He merely thinks that by doing so we cannot grasp completely what time is. As in the above quotation, he sometimes uses "pure duration" to denote the temporal aspect not captured by the spatial representation. This "pure" aspect constitutes duration as a temporal series together with its spatial, measurable aspect. It is natural to identify the former with the passage of time. ${ }^{3}$

Regarding the argument that Bergson rejected STR because it ignores duration, the important thing to note is that he accused science only of ignoring temporal passage. Apart from that, he admitted that science deals with other aspects of duration by measuring it. This does not explain why he insisted that the measured time must be absolute. As we have seen above, he admitted that the time shown by a clock can run synchronously with the time experienced by an observer, and that the first can even be used to measure the second. The question remains as to why he nevertheless believed that the times experienced by observers in different frames of reference do not diverge.

\footnotetext{
3 This suggests a comparison with John McTaggart's (1908) distinction between the A-series and the B-series, the second being the "spatial" side of time. That a B-series is devoid of passage is the standard interpretation, which Clifford Williams (1998) disputes from a Bergsonian perspective. However, McTaggart speaks of temporal passage exclusively with regard to the A-series and argues that there is no change in a B-series.
} 


\subsection{The real and the imaginary}

Most commentators seem to prefer the third explanation, which points to Bergson's distinction between "real" and "imaginary". According to this distinction, there are real and imaginary times as well as real and imaginary observers measuring these times: "The real is that which is measured by a real physicist, and the imaginary, that which is represented in the mind of the real physicist as measured by imaginary physicists" (Bergson 1965, p. 79). ${ }^{4}$

Consider the famous "twins paradox". In this thought experiment, one person remains on Earth, while the other flies into space and returns to Earth after, let us say, two hundred Earth years. According to STR, less time has passed for the space traveller than for the person on Earth. Bergson denies this, claiming that the same amount of time has passed for Peter and Paul, as he names the two: "If we said that the first flow lasted two hundred years, the other flow will also last two hundred years. Peter and Paul, earth and projectile, will have gone through the same duration and aged equally" (1965, p. 74).

For Bergson, relativistic time dilation is not a real phenomenon. The slowed down time ascribed to a moving system is imaginary, a mere fiction. But later, time dilation became an established physical fact, turning the distinction between the real and the imaginary into Bergson's "Achilles' heel", as Jimena Canales calls it, and "the reason why legions of readers would brand him as not having understood the theory of relativity" (Canales 2015, p. 52).

However, this standard objection to Bergson misses the fact that the distinction between real and imaginary time has a firm basis in STR. It corresponds to the distinction between proper time and coordinate time, with the former being the time that elapses at a certain location and can be measured by a clock resting at that location. That Bergson refers with "real time" to proper time is revealed in an appendix to the second edition of Duration and Simultaneity from 1923, where he writes about "real time, indicated by the real clock" $(1965$, p. 186) and about proper time as "the time that the clocks in the system will record" (p. 178). ${ }^{5}$

Coordinate time, on the other hand, is the time in a reference frame, running at the same speed everywhere in the frame. From the point of view of STR, there are at least two reasons for taking coordinate time as "not real", or perhaps "less real" than proper time. First, it is the result of a projection: the proper time at one location is projected on the entire frame. Physically speaking, this projection is achieved by the synchronisation of clocks (Rindler 2006, pp. 184-6). The second reason is that coordinate time cannot be measured, since what a clock measures is the proper time at its location. Bergson frequently alludes to this feature of coordinate time, arguing, for example, that the fictional times "are conventional times by definition, since they measure no real or possible duration" (1965, p. 119).

However, even though it makes some sense to say that proper time is real and coordinate time is not, the latter is not without physical meaning. Among other things, it is a tool for comparing the proper time on Earth with the proper time of Paul's

\footnotetext{
${ }^{4}$ In this citation, "imaginary" stands for the French fictif; in some other places, Bergson uses imaginaire.

5 On the identity of real time and proper time, see also Čapek (1971, p. 242).
} 
spaceship. Calculations employing this tool predict that less of Paul's time than of Peter's has elapsed when the former returns to earth. ${ }^{6}$ Bergson's error was to deny that this calculation has physical meaning, by denouncing coordinate time as "imaginary". This conclusion cannot be justified by the fact that coordinate time is derived from proper time and, in contrast to the latter, cannot be measured. Nor does all this explain why Bergson believed that the proper times in different frames of reference must run at the same pace, to which he referred as "the unity of real time" (1965, pp. 73 and $82)$.

\subsection{Intellectual intuition}

The three reasons discussed so far do not sufficiently explain why Bergson endorsed the unity of time. Neither the psychological origin of the concept of duration nor the criticism of spatialization, nor the distinction between the real and the imaginary, implies "the idea of a time common to all things" (1965, p. 47). Rather, this idea arises from Bergson's anti-Kantian conception of metaphysics. Countering physics with metaphysics in this way was certainly easier in 1922 than it is today. Apart from thought experiments, including the famous ride on a beam of light, Einstein's theory was based on the explanation of real experiments that had been known for some time-for example, Faraday's experiments on electromagnetic induction. ${ }^{7} \mathrm{New}$ verifications of the theory, such as Ives and Stilwell's experiment on time dilation (Rindler 2006, p. 80), still lay in the future. In other words, in 1922 there was plenty of room for purely metaphysical arguments against STR.

Bergson's metaphysical position had developed over the years. His first two books, published in 1889 and 1896, respectively, dealt with psychology and related metaphysical problems - in particular, freedom of the will and the relation of mind and body. Later, he developed a general metaphysics and presented it in "Introduction to Metaphysics", which includes a critical discussion of Immanuel Kant. Bergson regards him as a relativist who judged the absolute as unknowable because he erroneously rejected intellectual intuition as a valid source of knowledge: "Once the relation of science and metaphysics with 'intellectual intuition' is misunderstood, Kant has no difficulty in showing that our science is entirely relative and our metaphysics wholly artificial" (Bergson 1946, p. 230). While Kant considered intellectual intuition as impossible, Bergson made it the very basis of his own metaphysics: "A truly intuitive philosophy would realize the union so greatly desired, of metaphysics and science" (p. 227). ${ }^{8}$

Bergson understood metaphysics as intuitive knowledge of the absolute. By this definition, it is certainly true that Kant had separated science from metaphysics. However, Kant believed in a different type of metaphysics, defining it as transcendental philosophy that discloses the a priori conditions of experience. He thought that this

\footnotetext{
6 The exact interpretation of the twins paradox is surprisingly controversial. For a simple and clear exposition, see Maudlin (2012, pp. 77-83).

7 The Michelson-Morley experiment must be mentioned as well, but its significance for the emergence of STR is controversial (Topper 2013, ch. 6).

8 This is why John Mullarkey writes that "one could look upon Bergson's philosophy in general as a reversed Kantianism" (1999, p. 115).
} 
kind of metaphysics proves the unity of time: "the rule of the understanding, through which alone the existence of appearances can acquire synthetic unity in temporal relations, determines the position of each of them in time, thus a priori and validly for each and every time" (Kant 1998, A 215, B 262). ${ }^{9}$

It is rather ironic that Bergson's criticism of Kant was aimed at defending the unity of time that Kant himself had supported. Yet, Bergson recognised that Kant's metaphysics opened the door to relativism. The next step would be to dismiss the idea of a priori justification of absolute time as well. This is exactly what Einstein did: "I have never been able to understand the quest of the a priori in the Kantian sense" (Einstein 1954, p. 278). ${ }^{10}$

After the emergence of STR, Einstein replaced Kant as Bergson's opponent, and Einstein's theory replaced Kant's transcendental philosophy. Bergson assigned to intellectual intuition the task of uncovering the absolute in the realm of physics. In Duration and Simultaneity, he describes intuition as a kind of extension of one's own consciousness to the whole universe: "Thus is born the idea of a duration of the universe, that is to say, of an impersonal consciousness that is the link among all individual consciousnesses, as between these consciousnesses and the rest of nature" (1965, p. 45).

This intuitionist, anti-Kantian, and anti-relativist metaphysics helps to explain Bergson's belief in the unity of time. The dice were loaded from the start, when he took the side of metaphysics and defined it as intuitive knowledge of the absolute. By intuitively projecting himself into the universe, the philosopher hoped to recover the unity of time that physics had abandoned. No wonder a metaphysics conceived in this way goes astray.

\subsection{Common sense}

Speaking of Bergson's conception of metaphysics, we must also take into account another factor that has influenced this conception. Bergson frequently notices that a particular metaphysical statement agrees with common sense (sens commun). In general, he considers it advantageous when metaphysics and everyday thinking coincide. In the terminology coined by Peter Strawson $(1959$, p. 9), we may say that his ideal of metaphysics was "descriptive" rather than "revisionary".

In Matter and Memory, for example, Bergson defends common-sense realis$\mathrm{m}$-which says "that matter is precisely that which it appears to be" (1911, p. 80)—by pointing out the shortcomings of idealism and other forms of realism, such as Kant's realism of things-in-themselves. ${ }^{11}$ The defence of the unity of time through intellectual intuition is another case in point. Bergson claims that this unity is a hypothesis of

\footnotetext{
9 Perhaps Michael Friedman's comment on this passage is more intelligible: "All temporal relations are rather the products of an empirical construction whereby we objectively determine the appearances, as objects of a unified experience, by means of the a priori principles of the understanding" (Friedman 2013, p. 62).

10 Arthur Miller describes Einstein's epistemology as his “own version of Kant as viewed through the pages of, in particular, Hertz and Poincaré" (1998, p. 115). It is reported that Einstein had already read the Critique of Pure Reason as a teenager (1998, p. 170, note 36).

11 Common-sense realism has regained some popularity in the last decades; see, for example, Lemos (2004) and De Caro (2015).
} 
common sense (1965, p. 47) and even admits that the latter, in addition to philosophical argument, provides a reason for accepting this hypothesis (p. 78).

Since the hypothesis of the unity of time disagrees with STR, this shows that Bergson was sometimes misled when he tried to meet the requirements of common sense. However, the notion of philosophy as cooperating with common sense also has a less problematic application: If different interpretations of STR are available that equally fit the empirical data, Bergson would choose the one that is closest to everyday thinking. (We will soon see this methodology at work in the evaluation of eternalism.) Moreover, he believed that philosophy, when it listens to common sense, just follows the model of scientific theory building. Knowing that empirical research can force us to dismiss the guidelines of common sense, and that STR contradicts the pre-scientific understanding of time and space in many ways, he argued that "science runs counter to common sense only when strictly necessary" (1965, p. 35).

\section{Duration in growing blocks}

\subsection{Local passage and static eternalism}

Since Bergson's duration, or "real time", is identical to relativistic proper time, the passage of the latter implies the passage of the former. That in STR the passage of time is a local phenomenon pertaining to proper time was suggested, without reference to Bergson, by Čapek (1971), Clifton and Hogarth (1995), Dennis Dieks (2006) and others. The idea was earlier proposed by Howard Stein (1968, p. 15) and can even be traced back to the first decade after the development of STR when the physicist Alfred Robb wrote, "the only events which are really simultaneous are events which occur at the same place" (1914, p. 6). Although Robb did not speak of passage, but rather of the temporal order of events, the notion of local passage is based on this view of simultaneity.

The main alternative to local passage is the static conception of time, already mentioned in Sect. 2.2 above, to which I shall now refer as "static eternalism". ${ }^{2}$ In general, eternalism is the view that the past, present, and future exist. ${ }^{13}$ In static eternalism, this goes along with the denial of temporal passage, but not all eternalists adopt this view. The combination of eternalism with passage yields dynamic eternalism, which will be covered later. It is common in the philosophy of time to argue for static eternalism on the basis of STR, with the crucial issue being the relativity of simultaneity. Given a present event $\mathrm{P}$, determining which events are simultaneous with $\mathrm{P}$ depends on the choice of a reference frame, thus implying that the present is relative. If we assume that temporal passage is a process in which what is present becomes past, we cannot understand it as global passage everywhere in the universe. This may lead to the idea of

\footnotetext{
12 Static eternalism is also known as "B-theory", after McTaggart's (1908) "B-series".

13 Strictly speaking, temporal expressions such as "past", "present", and "future" need to be relativised to frames of reference in STR. To avoid these expressions altogether, eternalism can be defined as the view that all events in space-time exist (Savitt 2006, p. 123). As Savitt rightly notes (p. 112), "exists" and "is real" tend to be used interchangeably in this context. Accordingly, eternalism is often described as saying that the events are real. I go for "exist" because Bergson uses "real" not in this sense.
} 
local passage. Static eternalism, however, solves the problem by abandoning passage altogether.

A more general argument for abandoning passage, which does not depend on STR, is that physical theories do not refer to "past", "present", and "future". This argument persuaded J. J. C. Smart to dismiss these concepts as "anthropocentric" (1963, p. 132). While it is true that a physical theory is conceived, discussed, applied, tested, and so on in some present, this concerns scientific practice but not the theory's content. If the theory includes a variable $t$ for time, it does not distinguish a particular time point as the "present" one. Philosophers defending temporal passage may answer to this objection by stating that even if science does not need this concept, we need it in order to account for our experience. This, of course, is the very source of Bergson's belief in passage: "Pure duration is the form which the succession of our conscious states assumes when our ego lets itself live" (Bergson 1910, p. 100).

Most static eternalists, on the other hand, would not dispute that this is how we experience time; they would just add that this experience is illusionary. ${ }^{14} \mathrm{~L}$. A. Paul, for one, construes this debate as regarding an evaluation of inferences to the best explanation. What explains best why we experience the passage of time? Philosophers like Bergson think that the best explanation is the existence of temporal passage in the physical world, an explanation that favourably agrees with how non-philosophers envisage time. Static eternalists, by contrast, must explain our experience in a different way. Paul does this by claiming that "when we have an experience as of passage, we can interpret this as an experience that is the result of the brain producing a neural state that represents inputs from earlier and later temporal stages and simply 'fills in' the representation of motion or of changes" (2010, p. 352; footnote omitted).

Paul's argument is one possible explanation of temporal experience that static eternalists could endorse. However, since the present paper deals with Bergson's treatment of STR, a detailed discussion of the arguments exchanged between believers and deniers of temporal passage would go beyond its scope. It is important to note, though, that the meaning of "best" in "best explanation" is shaped by methodological principles that reflect basic philosophical decisions. On one side, there is science and reductionism, while on the other, there is common sense and temporal experience, whose authority must be explained away by those who position themselves on the former side.

I have already explained that for Bergson science is not the only measure of things. Even if the authority of temporal experience could be successfully explained away, we would not be forced to accept such an explanation. If it is possible to interpret STR in such a way as to retain the common-sense intuition of temporal passage, this interpretation is preferable to a reductionist metaphysics that abandons passage altogether. The identification of duration with proper time provides the key to such an approach. However, there is more to Bergson's metaphysics of passage than just this identification.

14 Only few philosophers go as far as to deny that time appears to pass (for example, Hoerl 2014 and Farr 2020). 


\subsection{Growing block theory and dynamic eternalism}

What is still missing in our reconstruction of Bergson's philosophy of time is the "survival of the past" (1911, p. 193). Here, "survival" means that the past exists and grows as the present becomes the past. It could be argued that this idea transcends common sense, if we assume that the latter negates the existence of the past. Thus, the survival of the past would contradict the methodological principle that I have just ascribed to Bergson.

However, most people would also acknowledge a fundamental asymmetry between the past and the future. While the past influences our lives in many ways and cannot be changed by our actions, we, in turn, influence the future. In addition, past and future are subject to different attitudes: there is memory of the past but not of the future; anticipation of the future but not of the past, and so on. We are "future-biased with respect to our own bad experiences" (Hare 2013, p. 519), that is, we prefer these experiences to be in the past rather than in the future.

All this shows that everyday thinking does not treat the past in the same manner as the future, and this speaks in favour of Bergson's asymmetrical account, which allows to understand the asymmetries in terms of the difference between existence and non-existence. Our influence does not extend to the past because existing events cannot be made non-existent, while non-existent events can be created or prevented in the future. Memory is a relation between existing events of consciousness and existing events of the past, whereas anticipation is no relation at all (given that intentionality is not a true relation). We are future-biased with respect to our bad experiences because we fear that they will come into existence and hope they will not. In contrast, you cannot fear an event that already exists, such as yesterday's visit to the dentist.

C. D. Broad is usually credited for having been the first to propose the survival of the past: "Whatever is has become, and the sum total of the existent is continually augmented by becoming. There is no such thing as ceasing to exist; what has become exists henceforth forever" (1923, p. 69). ${ }^{15}$ Yet, as early as 1896, in Matter and Memory, Bergson had been thinking in the same direction after having acknowledged the existence of duration outside of consciousness. In that book, the survival of the past takes on two forms: one is memory, in the realm of consciousness, and the other is the continuing existence of the past in the physical world. Addressing an opponent who denies the latter, Bergson makes the following statement: "Either, then, you must suppose that this universe dies and is born again miraculously at each moment of duration, or you must attribute to it that continuity of existence which you deny to consciousness, and make of its past a reality which endures and is prolonged into its present" (1911, p. 192).

When it comes to the existence of the universe, we must choose between the "miracle" of beginning and ceasing to exist in the present, on the one hand, and the growing past, on the other. That Bergson prefers the second alternative is made clear in the 1907 book Creative Evolution, where we read that "the past, always moving on, is

\footnotetext{
15 Emily Thomas (2019) maintains that a view such as this can already be found some years earlier in Samuel Alexander, and that Broad might even have taken it from that source. A well-known recent defence of the growing block theory comes from Michael Tooley (1997). Bergson would have liked his appreciation of absolute simultaneity.
} 
swelling unceasingly with a present that is absolutely new" (1922, p. 210). Statements such as these strongly support the view that Bergson endorsed "realism towards the past" (Mullarkey 1999, p. 3).

With regard to Bergson's interpretation of STR, however, the case is not that clear. For example, the following sentence from Duration and Simultaneity apparently confirms presentism, the sole existence of the present: "duration is essentially a continuation of what no longer exists into what does exist" (1965, p. 49). Overall, it seems that Bergson had sympathies for both views or changed his mind in later years. As to the survival of the past, Čapek (1971, p. 154) is certainly right when he writes that Bergson "was never as explicit on this point" as Broad and other philosophers. However, since our question is what Bergson should have said about STR, we are interested in which theoretical resources were available to him. The quotations from Matter and Memory and Creative Evolution regarding the existence of the past at least prove that the ground was prepared for the growing block theory, as the "survival of the past" is known today. I will later indicate that Bergson's distinction between actual and virtual existence provides another reason for construing his philosophy along this line.

Before I go on with this topic, I would like to add a few notes about dynamic eternalism, which is the result of adding passage to eternalism. ${ }^{16}$ Some proponents of this view are content with adopting passage as a fundamental fact that cannot be explained by more primitive notions (Maudlin 2007, pp. 107 and 172). Most dynamic eternalists, however, try to give an account of what passage is, and here, the metaphor of the moving spotlight has become influential in recent years. The present is said to be illuminated by a "spotlight" that moves towards the (already existing) future.

Several theories have been developed that purport to provide this metaphor with literal meaning, explaining the metaphorical moving spotlight in very different ways. It has been suggested that the spotlight shines on the temporary fundamental property of absolute presentness (Deasy 2015, p. 2077), or on some relative presentness, for example, on what is present from the perspective of a second time dimension or a second space-time (Skow 2015, pp. 46 and 161). Each suggestion involves metaphysical implications that cannot be discussed here. For our purposes, the crucial assumption that moving spotlight theories share with all types of eternalism is that the future exists. ${ }^{17}$ This assumption contradicts Bergson's growing block view, which construes temporal passage as "the ever-renewed creation which reality, whole and undivided, accomplishes in advancing" (1922, p. 229).

Like the static eternalist who argued that the experience of passage is illusionary, the dynamic eternalist might reply that the experience of creation is just an illusion (disagreeing, though, with the static eternalist on the illusionary character of passage).

\footnotetext{
16 Following Timothy Williamson (2013), some have replaced talk of eternalism with talk of "permanentism", which is the view that always everything always exists. In the present paper, I do not consider this recent shift of discourse, which is primarily fueled by modal logics. Let me just note that some modern moving spotlight theories (see below) are composed in terms of permanentism.

17 This is also true for the rather unusual moving spotlight theory by Ross Cameron, in which passage is associated with the ageing of things: "as time passes, how things are simpliciter changes" (2015, p. 159). Cameron does not regard this as a passage through the B-series, yet agrees with eternalists that non-present (past and future) things exist (see p. 133).
} 
However, as in the case of static eternalism, Bergson's methodology commits him to follow the lead of common sense, if this is consistent with science. Having the choice between two contradicting philosophical interpretations of our relation to the future, we should pick the less revisionary one. As to this criterion, the view that the future does not exist is arguably more widespread in pre-scientific and pre-philosophical thinking than the opposite view. Moreover, I suspect that for most people the existence of the past is easier to accept than the existence of the future. ${ }^{18}$

\subsection{Growing past light cones}

Given that neither static nor dynamic eternalism was an option for Bergson, the question arises as to why he affirmed the survival of the past and did not simply stick to presentism. The answer is that he again agrees with common-sense realism in assuming that the things we perceive do exist, knowing, at the same time, that these things are not present. When I perceive an object, the signals coming from that object need some time to enter my sense organs, which is true for distant things, such as the sun, as well as for nearer ones, such as my computer. Accordingly, Bergson writes in Matter and Memory: "Practically we perceive only the past, the pure present being the invisible progress of the past gnawing into the future" (1911, p. 194).

He reacts to this fact by distinguishing between actual and virtual existence. ${ }^{19} \mathrm{My}$ body is a centre of action and perception in the material world. Perceiving this world means that material objects produce sensory stimulations in my body. The objects perceived are virtual, whereas what happens in the body is actual, which implies the actuality of the present and the virtuality of the past (1911, p. 173). More precisely, this only implies the virtuality of the perceptible past - that is, of that part of the past which can causally affect my body. In STR, this causal/perceptible past is given by a past light cone.

The picture that emerges is this: my body exists, as does the past that I can perceive, in principle. As time passes, this existing past grows along the body's path through space-time. According to Bergson, "we may speak of the body as an ever advancing boundary between the future and the past, as a pointed end, which our past is continually driving forward into our future" (1911, p. 88). Later in the book (p. 197), he illustrates the structure of memory with the drawing of a cone that resembles a light cone of STR. Unfortunately, he adds a "shifting plane of experience" to the tip of the cone and speaks of "universal becoming" (p. 196), showing once again a Newtonian prejudice. For all the differences, however, this illustration can be seen as a step towards a relativistic growing block theory of temporal passage.

The variant of this theory that provides the best match to Bergson's account is the "pointy relativistic growing block theory", as Fabrice Correia and Sven Rosenkranz call it (2018, p. 150). Here, the "block" is the increasing past light cone "dragged

\footnotetext{
18 The famous words in Requiem for a Nun indicate that literature is sensitive to such things: "The past is never dead. It's not even past" (Faulkner 1951, p. 92).

19 Partly under the influence of Deleuze (1988), it has become customary to use "actual" instead of "real". Bergson employs actuel and réel interchangeably in the relevant contexts, but the second more often. I have chosen "actual" to prevent the confusion of "actual versus virtual" with "real versus imaginary".
} 
along" by the body on its path through space-time. I would suggest that this is the view that Bergson should have adopted, since it is not only compatible with STR but retains constitutive elements of his philosophy of time-above all, the (virtual) existence of the past and the existence of temporal passage in the physical world. The passage of proper time is part of the picture because the past light cone is the sum of all possible trajectories leading to the present. Proper time passes along these paths.

To get a more precise idea of the pointy relativistic growing block theory, we must first bring locality back into the picture, which means that the present-the tip of the light cone-is a point of space-time. The remaining cone comprises those areas of the past from which signals can reach the tip. It includes the cone's surface, which contains the trajectories of light rays, whereas signals reaching the top from inside the cone travel below the speed of light.

Since the point at the top of the cone takes the place of the body in Bergson's account, an object without extension substitutes a spatially extended one. ${ }^{20}$ This raises a problem, which fortunately can easily be solved. Let us assume that $S$ is the space-time point in question and that this point lies somewhere within the boundaries of my body. Thus, my body does not presently exist at $\mathrm{S}$, at least not in its entirety. Bergson, though, seems to take the whole body to be present. To eliminate this conflict, we may assume that the body is a mereological fusion of its parts and that such a fusion is present wherever one of its parts is present (Correia and Rosenkranz 2018, p. 151). In this derived sense of "present", then, my body can be said to be present at all points within its boundaries. However, only point-like things can be present in the strict sense of this word.

Another objection that has been put forward against the pointy relativistic growing block theory is related to persistence (Correia and Rosenkranz 2018, p. 152). ${ }^{21}$ If $\mathrm{S}$ is the tip of the light cone, we may say that the entire cone (including $\mathrm{S}$ itself) exists relative to $S$. Most things exist relative to $\mathrm{S}$ without persisting until $\mathrm{S}$, since only objects whose space-time trajectories go through $S$ persist up to this point. For example, when I see my hands, it is plausible to locate $S$ where my head is, perhaps close to my eyes or inside my brain. My hands reflect light that enters my eyes, but they do not persist until S. Under the mereological assumption described above, we could again say that the hands persist in the derived sense, as my whole body exists in this sense at $\mathrm{S}$. In a strict sense of persistence, however, my hands do not persist until S. In addition, if we consider objects existing outside my body, the derived sense of persistence is completely out of place. My computer screen, for one, exists relative to $\mathrm{S}$ but does not persist until $\mathrm{S}$.

The force of this objection rests on the premise that observable objects, such as hands and screens, must persist until they are perceived, from which it is concluded that the pointy relativistic growing block theory is inadequate, because it does not

\footnotetext{
20 I am referring to spatial rather than spatiotemporal extension, because, in the passage quoted before, Bergson speaks of the body as a "boundary" between future and past; a "pointed end".

21 The objection is prefigured in Savitt (2000, p. 568). It is the main reason why Correia and Rosenkranz prefer a different version of relativistic growing block theory in which existence comprises not only the past light cone but also the area outside the past and future cones, the "elsewhere" being space-like separated from S. Other possibilities of defining existence are nicely compared by Sam Baron (2018, p. 5), albeit in a presentist setting, so "present" stands for "existent".
} 
permit such persistence. Those raising this argument regard the premise as intuitively reasonable, yet it is by no means clear what reasons could be offered in its support. ${ }^{22}$ The growing block theory already admits that the perceived objects exist relative to the point where perceptual sensation occurs. Why should this additionally require that the trajectories of these objects cross that point? $?^{23}$

I suggest accepting that perceived objects do not persist up to the event of perception. What is more, we can make a virtue of this necessity and adopt non-persistence as a characteristic feature of the virtual existence of things. Both actual and virtual existence are relative: to say that something exists is to say that it exists relative to some space-time point $S$. Actual existence relative to $S$ is presentness at $S$, whereas virtual existence means to be located in the causal past of $S$. Thus, if we refer to space-time points (events) rather than persisting things, only $\mathrm{S}$ has actual existence relative to $\mathrm{S}$. However, with regard to persisting things in the causal past of $\mathrm{S}$, we have just learned that things that do not persist until $\mathrm{S}$ have virtual existence relative to $\mathrm{S}$.

Since STR is in many ways at odds with pre-scientific opinions, any theory of time that accepts STR will include some statements that take getting used to. That the present is just a point and that time passes in the form of growing blocks are probably the most salient statements of this kind in the pointy relativistic growing block theory. In return, this theory tells us something about the nature of temporal passage. Passage is the growth of past light cones. Regarding Bergson, the most important thing is that he could have found in this conception many of his own opinions about time.

\section{Conclusion}

Based on his account of duration, Bergson defended Newton's absolute time against the revolution in the physical world view initiated by Einstein. In Sect. 2, I discussed possible reasons for Bergson's criticism of STR. There is the idea, expressed by Einstein himself, that Bergson objectified psychological time. Some philosophers have argued that he feared that STR does not provide a place for temporal passage. Others blamed his distinction between the real and the imaginary. While there is some truth to each of these three explanations, they are incomplete without taking into account Bergson's general metaphysical outlook, which relies on the notion of intellectual intuition of the absolute and which is related to his affirmation of common sense.

Section 3 proceeded from the observation that STR admits the passage of proper time. We have seen that for Bergson proper time is real time. Although acknowledging coordinate time as well, he unfortunately misjudged it as being merely imaginary. Since his opponents later emphasised this and other misinterpretations of STR, they tended to overlook that relativistic proper time fits well with Bergson's durée.

\footnotetext{
22 Correia and Rosenkranz maintain, without explanation, that "I have every reason to believe that my limbs have persisted" (2018, p. 152).

${ }^{23}$ Note that all this pertains to persistence along a path crossing the location of perception. In general, it can be argued that persisting things, particularly clocks, are indispensable for STR. This holds regardless of whether the notion of a clock is an independent concept (Bacelar Valente 2016) or can be derived from the propagation of light (Bacelar Valente 2019).
} 
I have explained why neither static nor dynamic eternalism are acceptable based on Bergson's methodological premises, which give a place to temporal experience and everyday thinking alongside science and metaphysics. These premises imply that we are justified in believing in temporal passage and understanding it as creation of new existence, as long as this is compatible with STR. Bergson anticipated the growing block theory of time years before Broad presented it in 1923. This theory meets all requirements if it does not construe the universe as a single growing block. The pointy relativistic variant, which divides the universe into blocks of growing past light cones, not only agrees with STR but also with much of Bergson's philosophy of time, while avoiding his Newtonian prejudices.

Acknowledgements Open access funding provided by University of Innsbruck and Medical University of Innsbruck.

Open Access This article is licensed under a Creative Commons Attribution 4.0 International License, which permits use, sharing, adaptation, distribution and reproduction in any medium or format, as long as you give appropriate credit to the original author(s) and the source, provide a link to the Creative Commons licence, and indicate if changes were made. The images or other third party material in this article are included in the article's Creative Commons licence, unless indicated otherwise in a credit line to the material. If material is not included in the article's Creative Commons licence and your intended use is not permitted by statutory regulation or exceeds the permitted use, you will need to obtain permission directly from the copyright holder. To view a copy of this licence, visit http://creativecommons.org/licenses/by/4.0/.

\section{References}

Arrhenius, S. (1967). Presentation speech: Nobel prize in physics 1921. In Nobel lectures physics 1901-1921 (pp. 479-481). Amsterdam: Elsevier.

Bacelar Valente, M. (2016). Proper time and the clock hypothesis in the theory of relativity. European Journal for Philosophy of Science, 6, 191-207.

Bacelar Valente, M. (2019). Time in the theory of relativity: Inertial time, light clocks, and proper time. Journal for General Philosophy of Science, 50, 13-27.

Baron, S. (2018). Time, physics, and philosophy: It's all relative. Philosophy Compass, 13, e12466.

Bergson, H. (1910). Time and free will: An essay on the immediate data of consciousness (F. L. Pogson, Trans.). London: George Allen \& Unwin.

Bergson, H. (1911). Matter and memory (N. M. Paul \& W. S. Palmer, Trans.). London: George Allen \& Unwin.

Bergson, H. (1922). Creative evolution (A. Mitchell, Trans.). London: Macmillan.

Bergson, H. (1946). The creative mind (M. L. Andison, Trans.). New York: Philosophical Library.

Bergson, H. (1965). Duration and simultaneity (L. Jacobson, Trans.). Indianapolis: Bobbs-Merrill.

Broad, C. D. (1923). Scientific thought. London: Kegan Paul.

Cameron, R. P. (2015). The moving spotlight: An essay on time and ontology. New York: Oxford University Press.

Canales, J. (2015). The physicist and the philosopher: Einstein, Bergson, and the debate that changed our understanding of time. Princeton: Princeton University Press.

Čapek, M. (1971). Bergson and modern physics: A reinterpretation and re-evaluation. Dordrecht: Reidel.

Clifton, R., \& Hogarth, M. (1995). The definability of objective becoming in minkowski spacetime. Synthese, 103, 355-387.

Correia, F., \& Rosenkranz, S. (2018). Nothing to come: A defence of the growing block theory of time. Berlin: Springer.

De Caro, M. (2015). Realism, common sense, and science. The Monist, 98, 197-214.

Deasy, D. (2015). The moving spotlight theory. Philosophical Studies, 172, 2073-2089.

Deleuze, G. (1988). Bergsonism (H. Tomlinson \& B. Habberjam, Trans.). New York: Zone Books. 
Dieks, D. (2006). Becoming, relativity and locality. In D. Dieks (Ed.), The ontology of spacetime (pp. 157-176). Amsterdam: Elsevier.

Einstein, A. (1954). Ideas and opinions (S. Bargmann et al., Trans.). New York: Crown.

Einstein, A. (2012). Collected papers. In D. Kormos Buchwald, J. Illy, Z. Rosenkranz, \& T. Sauer (Eds.), The Berlin years: Writings \& correspondence January 1922-March 1923 (Vol. 13). Princeton: Princeton University Press.

Farr, M. (2020). Explaining temporal qualia. European Journal for Philosophy of Science, 10, 8.

Faulkner, W. (1951). Requiem for a nun. New York: Random House.

Friedman, M. (2013). Kant's construction of nature: A Reading of the metaphysical foundations of natural science. Cambridge: Cambridge University Press.

Hare, C. (2013). Time-The emotional asymmetry. In H. Dyke \& A. Bardon (Eds.), A companion to the philosophy of time (pp. 507-520). Oxford: Wiley-Blackwell.

Hoerl, C. (2014). Do we (seem to) perceive passage? Philosophical Explorations, 17, 188-202.

Kant, I. (1998). Critique of pure reason (P. Guyer \& A. W. Wood, Trans.). Cambridge: Cambridge University Press.

Lemos, N. (2004). Common sense: A contemporary defense. Cambridge: Cambridge University Press.

Maudlin, T. (2007). The metaphysics within physics. New York: Oxford University Press.

Maudlin, T. (2012). Philosophy of physics: Space and time. Princeton: Princeton University Press.

McTaggart, J. E. (1908). The unreality of time. Mind, 17, 457-474.

Miller, A. I. (1998). Albert Einstein's special theory of relativity: Emergence (1905) and early interpretation (1905-1911). New York: Springer.

Mullarkey, J. (1999). Bergson and philosophy. Edinburgh: Edinburgh University Press.

Paul, L. A. (2010). Temporal experience. Journal of Philosophy, 107, 333-359.

Ray, C. (1991). Time, space and philosophy. London: Routledge.

Rindler, W. (2006). Relativity: Special, general, and cosmological (2nd ed.). New York: Oxford University Press.

Robb, A. (1914). A theory of time and space. Cambridge: Cambridge University Press.

Savitt, S. F. (2000). There's no time like the present (in Minkowski spacetime). Philosophy of Science, 67 (Supplement), 563-574.

Savitt, S. F. (2006). Presentism and eternalism in perspective. In D. Dieks (Ed.), The ontology of spacetime (pp. 111-127). Amsterdam: Elsevier.

Skow, B. (2015). Objective becoming. New York: Oxford University Press.

Smart, J. J. C. (1963). Philosophy and scientific realism. London: Routledge \& Kegan Paul.

Stein, H. (1968). On Einstein-Minkowski space-time. Journal of Philosophy, 65, 5-23.

Strawson, P. F. (1959). Individuals: An essay in descriptive metaphysics. London: Methuen.

Thomas, E. (2019). The roots of C. D. Broad's growing block theory of time. Mind, 128, 527-549.

Tooley, M. (1997). Time, tense, and causation. Oxford: Clarendon.

Topper, D. R. (2013). How Einstein created relativity out of physics and astronomy. New York: Springer.

Williams, C. (1998). A Bergsonian approach to A- and B-time. Philosophy, 73, 379-393.

Williamson, T. (2013). Modal logic as metaphysics. Oxford: Oxford University Press.

Publisher's Note Springer Nature remains neutral with regard to jurisdictional claims in published maps and institutional affiliations. 